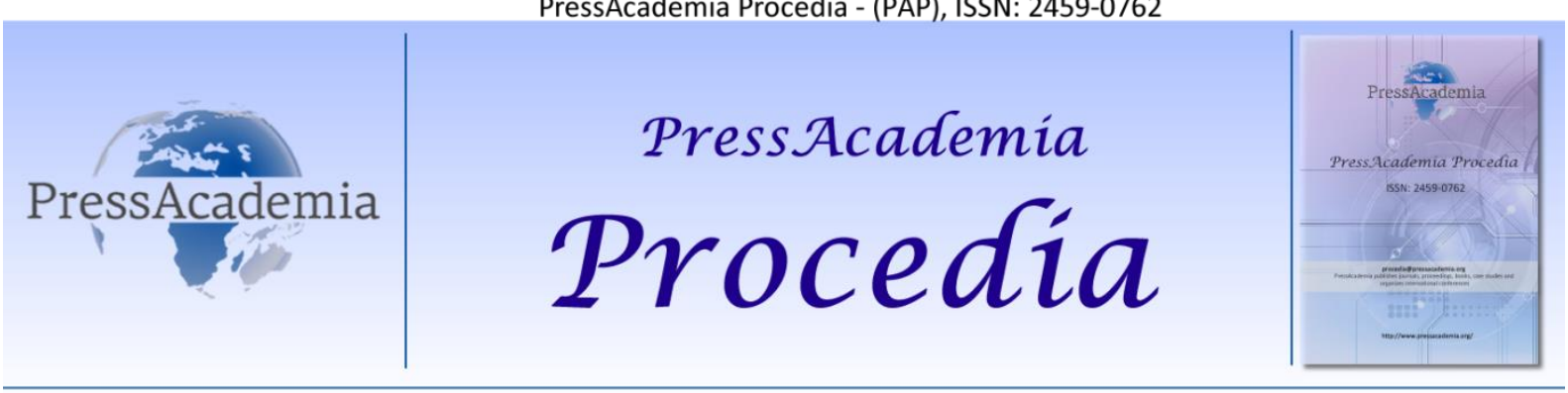

2nd World Conference on Technology, Innovation and Entrepreneurship

May 12-14, 2017, Istanbul, Turkey. Edited by Sefer Şener

\title{
INVESTIGATING THE POTENTIAL OF DATA ANALYTICS SOLUTIONS IN MARITIME INDUSTRY
}

\author{
DOI: 10.17261/Pressacademia.2017.573 \\ PAP-WCTIE-V.5-2017(11)-p.67-70
}

Omer Soner ${ }^{1}$, Metin Celik ${ }^{2}$

${ }^{1}$ Department of Maritime Transportation \& Management Eng., Istanbul Technical University, Tuzla 34940, Istanbul, Turkey

${ }^{2}$ Department of Marine Eng., Istanbul Technical University, Tuzla 34940, Istanbul, Turkey

\begin{abstract}
Recently, enhancing the data collection and utilization in maritime field is one of the key issue. At this stage, the maritime authorities seek for applicable solutions through improving the operational processes of key stakeholders such as ship operators, shipyards, offshore structures, ports \& terminals, etc. This study reviews the existing data analytics solutions derived by research groups, classification societies, and technology providers. Considering the operational level integration requirements, the potential of the existing solutions in safety, efficiency, environmental sensitiveness and other performance indicators is determined. In conclusion, this study contributes to identification of the challenges and opportunities in order to extent data analytics applications to maritime field.
\end{abstract}

Keywords: Maritime industry, data analytics, operations management

\section{INTRODUCTION}

It's a common believe that data centred decision making is one of the leading factors that changing all aspects of the modern industries. Data analysis have been considered as the competitive differentiator, since an increase in output and productivity becomes more critical for many industries, where fierce competition takes place (Wang et al. 2015). New technologies have increased the capacity of capturing, storing, processing, presenting, and visualising of data. These data is used for many purposes, to illustrate; performance monitoring, condition-based and predictive maintenance, optimisation across systems, and system overview of operations ( $L \varnothing \mathrm{voll} \&$ Kadal, 2014). A research shows that companies, who take advantage of the data analytic models, have improved their output and productivity rate about 5-6 \% (Brynjolfsson et al. 2011). Therefore; it is not surprising that data analysis has already had a considerable impact on many industries, such as; maritime, aviation, health, and energy.

The maritime industry is subject to continuous demand in terms of cost, energy efficiency, environmentally friendly, timely delivery and economies of scale. Hence; International Maritime Organization (IMO) have introduced numerous conventions, and regulations to achieve these fundamental aims. According to International Convention for the Safety of Life at Sea (SOLAS); Voyage Data Recorder (VDR) is required to gathering specified data on board ship (SOLAS, 1974). In the environmental perspective; the MRV (Monitoring, Reporting, and Verification) regulation aims to quantify and reduce $\mathrm{CO} 2$ emissions from shipping (EU, 2014). Moreover, the e-navigation system is another striking development in the maritime industry that improves the collection and integration of shipboard data. The International Association of Lighthouse Authorities (IALA) is defined e-navigation as the unified collection, integration, exchange, and analysis of marine information on board and ashore to enhance safety and security at sea and protection of the marine environment (IALA, 2007). Even if the maritime authorities have imposed the data based improvement in all aspects of the industry, an inadequate number of research and project have been conducted within the maritime literature and maritime industry. Therefore; investigating the potential of data analytics solutions in maritime industry has a prominent important. The motivation of this paper is to review the data analytics related existing attempt in maritime domain. This paper organized as follows; motivation behind the study is presented in this section. In the second section, data centred studies and projects in maritime literature are investigated. Next, data analytics challenges and opportunities in maritime domain are fairly 
discussed. In the last section, the potential of data analytics are underlined and possible solutions are suggested to overcome certain obstacles.

\section{MARITIME DATA ANALYTICS}

In this section, data analytics related studies and projects have been investigated. Data analytics applications and studies in maritime transportation can be divided following main areas; technical operation and maintenance, energy efficiency, safety performance, management and monitoring of accident and environmental risks from shipping traffic, commercial operation, and automation of ship operations (Løvoll \& Kadal, 2014). In energy efficiency consideration; Baldi et al. (2014) have developed a methodology to analyse the energy flows of an entire ship with the goal of providing a better understanding of how energy is used on board ships. Perera and Mo (2016-a) have proposed data analysis techniques to understand marine engine operating regions as a part of the ship energy efficiency management plan (SEEMP). In order to improve ship energy efficiency under various emission control measures, SEEMP requires to collecting and analysing vessel performance and navigation data. Coraddu et al. (2017) have focused on the issue of fuel consumption prediction and trim optimisation of a vessel in real operations based on the data that gathered on board ship.

Regarding the operational efficiency related studies; Mak et al. (2015) have devoted a research for analysing the operational data for speed optimization in calm sea states and the development of a trim optimization software. Dobrkovic et al. (2015) have addressed the problem of "long term prediction" - the ability to estimate future position of a vessel at least 24 hours in advance for a specific region (the North Sea connecting the Netherlands and United Kingdom). Perera (2016) have developed the statistical filter based sensor and data acquisition (DAQ) fault detection for ship performance and navigation information. Perera and Mo (2016-b) have specified the marine engine operating regions under principal component analysis (PCA) to evaluate ship performance and navigation behaviour. Environmental aspects is another subtopic that have been investigated, such as; Leonardi and Browne (2010) have proposed a method for the calculation of the maritime sector' carbon footprint, Perera and Mo (2016-c) have presented an overview of emission control based energy efficiency measures in the ship operation, and Bilgili and Celebi (2016) calculate the total emissions produced during a total 80,000 DWT load by two different bulk carrier ships.

Moreover; the FRAM Project is a voluntarily joint project that aimed to become more energy efficient and environmentally friendly by measure, report and verify $\mathrm{CO} 2$ emissions on ships. The Hull Risk Profiler is one of the maritime industry data centred applications. The Hull Risk Profiler enables to immediately assess the risk associated with an owner, manager, fleet or an individual vessel. On the other hand, the OstiaEdge Monitoring Suite enables improved use of on board data to help implement a condition-based maintenance. Certain Logistics firm are annually saving about the 100 million dollars since real-time analysis helps them to make contingency plans for different situations from route planning to general reductions in speed (Løvoll \& Kadal, 2014). The AMINESS platform has aimed to integrate information from real-time vessel movements, weather data, traffic patterns, information on type and cargo of vessels, environmental data to suggest environmentally optimal safe route planning and deliver real-time alerts for ships (Giannakopoulos et al. 2014). Smart Ship Application Platform Project (SSAP Project) is one of the joint industry projects that consists of 27 member organizations. Main motivation of the project has utilized such application services to achieve optimum ship operation in terms of safety and energy efficiency (Ando, 2014). The studies that have been investigated clearly shows that in maritime domain there is still room for the expansion of the data centred applications and research. Moreover, data analytics have offered substantial opportunities that increase the maritime transportation' competitiveness. Therefore, identifying the challenges and opportunities have become a critical issue in order to extent data analytics applications in the maritime field.

\section{CHALLENGES AND OPPURTUNIES}

Most of the times, maritime transportation is considered as a conservative industry, so it takes a time to convince a traditional industry to fully integrate with the new data-driven age. However, required perspective should be able to understand this new age' challenges and opportunities. Therefore, maritime authorities and maritime researchers have investigated this issue. Koga (2015) have identified four major data analytics challenges, which are; sound competitive conditions, human resources, technology, and security. In the first category, the privacy issue, near monopoly of data providers and data governance have been investigated. At the second category, human resources with certain expertise for dealing with data analytics shortage is underlined. Next, technology perspective is analysed with respect to the availability of powerful tools, flexibility, data integration, correlation and causation, and collection biases. In the end, security perspective is investigated considering the unlawful control of device/machine and abusive insertion, update, and deletion of data. Rødseth et al. (2016) have investigated the obstacles to efficient collection of ship data on board. The study have emphasized cost and quality of on-board sensors and data acquisition systems, data ownership and technical obstacles to the effective collection and use of data on ships. Although the new technologies have made possible to collect all the data on board ship, these data are not readily available to analyse. Therefore; the owner or operator is likely to pay a high price for getting access to them. At this point, incompatible data formats for many types of data acquisition systems on a ship 
makes difficult to observe and treat these data in a unified manner. E-navigation has offered a possible solution, which called "Common Maritime Data Structure" (IHO, 2010). On the other hand, high sea satellite communication still limits the ship-shore communication, while land-based communication systems offer relatively competitive low costs and high capacity. Even if the all challenges that maritime shareholders have encountered with the data analytics applications, it's still have huge potential to improve the output and productivity in the maritime industy. Data analytics application can be used not just the real-time decision support systems, but also long term performance monitoring whether ship or fleet. Besides, maritime shareholders can also take advantage of the data analytic to increase the energy efficiency and reduce the environmental effects on the marine environment. Condition-based and predictive maintenance are also current issues that data analytics have great potential to deal with them.

\section{CONCLUSION}

The study have investigated the potential of data analytics in the maritime industry. In order to reveal the actual potential, the study have analysed challenges and opportunities that maritime shareholders have been encountered with data analytics application. Data acquisition problems are one of the fundamental challenges that maritime researchers constantly have to deal with. Even if the certain data is available on ship, accessing these data is required to strict regulatory development, and high cost infrastructure systems. Data analyst shortages is another considerable problems in the maritime industry. Securing the data and its provider, data management related problems have also generated essential restriction on the data analytics applications. However, data analytics have offered huge potential to increase the maritime competitiveness. Data analytics can be used to performance monitoring, condition-based and predictive maintenance, optimisation across systems, and system overview of operations in maritime industry. Therefore, data centred decision making related studies, and projects are urgently needed in the maritime industry.

\section{REFERENCES}

Ando, H. (2014). Smart Ship Application Platform Project (SSAP Project).

Baldi, F., Johnson, H., Gabrielii, C., \& Andersson, K. (2014). Energy analysis of ship energy systems-the case of a chemical tanker. Energy Procedia, 61, 1732-1735.

Bilgili, L., \& Celebi, U. B. (2016). Emission Routing in Maritime Transportation. In Energy, Transportation and Global Warming (pp. 837-849). Springer International Publishing.

Coraddu, A., Oneto, L., Baldi, F., \& Anguita, D. (2017). Vessels fuel consumption forecast and trim optimisation: A data analytics perspective. Ocean Engineering, 130, 351-370.

Dobrkovic, A., lacob, M. E., \& van Hillegersberg, J. (2015, October). Using machine learning for unsupervised maritime waypoint discovery from streaming AIS data. In Proceedings of the 15th International Conference on Knowledge Technologies and Data-driven Business (p. 16). ACM.

E. Brynjolfsson, L. M. Hitt, and H. H. Kim, "Strength in Numbers: How Does Data-Driven Decisionmaking Affect Firm Performance?" SSRN Electronic Journal, 2011.

EU, 2014. Proposal for a Regulation of the European Parliament and of the Council on the Monitoring, Reporting and Verification of Carbon Dioxide Emissions From Maritime Transport and Amending Regulation (EU) No. 525/2013-Political Agreement. Available at: 〈 http://register.consilium.europa.eu/doc/srv?l=EN\&f=ST\%2016238\%202014\%20INIT〉.

Giannakopoulos, T., Vetsikas, I. A., Koromila, I., Karkaletsis, V., \& Perantonis, S. (2014, May). Aminess: a platform for environmentally safe shipping. In Proceedings of the 7th International Conference on PErvasive Technologies Related to Assistive Environments (p. 45). ACM.

IALA. The IALA definition and vision for e-Navigation. E-NAV2-output 11 (March 2007)

IHO, S. (2010). 100, Universal Hydrographic Data Model. Robert Ward, Barrie Greenslad.

International Convention for the Safety of Life at Sea, 1974. IMO. (1974).

Koga, S. (2015). Major challenges and solutions for utilizing big data in the maritime industry.

Leonardi, J., \& Browne, M. (2010). A method for assessing the carbon footprint of maritime freight transport: European case study and results. International Journal of Logistics: research and applications, 13(5), 349-358.

Løvoll, G., \& Kadal, J. C. (2014). Big data-the new data reality and industry impact. DNV GL.

Mak, L., Seo, D. C., Kuczora, A., \& Sullivan, M. (2015, May). Vessel Performance Analysis and Fuel Management. In ASME 2015 34th International Conference on Ocean, Offshore and Arctic Engineering (pp. V011T12A052-V011T12A052). American Society of Mechanical Engineers. 
Perera, L. P. (2016). Statistical Filter based Sensor and DAQ Fault Detection for Onboard Ship Performance and Navigation Monitoring Systems. IFAC-PapersOnLine, 49(23), 323-328.

Perera, L. P., \& Mo, B. (2016-a). Data analysis on marine engine operating regions in relation to ship navigation. Ocean Engineering, 128, $163-172$.

Perera, L. P., \& Mo, B. (2016-b). Marine Engine Operating Regions under Principal Component Analysis to evaluate Ship Performance and Navigation Behavior. IFAC-PapersOnLine, 49(23), 512-517.

Perera, L. P., \& Mo, B. (2016-c). Emission control based energy efficiency measures in ship operations. Applied Ocean Research, 60, 29-46.

Rødseth, $\emptyset$. J., Perera, L. P., \& Mo, B. (2016). Big data in shipping-Challenges and opportunities. In Proceedings of the 15th International Conference on Computer and IT Applications in the Maritime Industries (COMPIT 2016), Lecce, Italy, May 2016, (361-373).

Wang, H., Osen, O. L., Li, G., Li, W., Dai, H. N., \& Zeng, W. (2015, November). Big data and industrial internet of things for the maritime industry in northwestern Norway. In TENCON 2015-2015 IEEE Region 10 Conference (pp. 1-5). IEEE. 